\title{
Hepatitis-Bs antigen in an isolated Indian population of southern Venezuela: a family study
}

\author{
A. SOYANO, Z. LAYRISSE, M. LAYRISSE, AND J. V. NEEL 1 \\ From the Instituto Venezolano de Investigaciones Cientificas, Caracas, Venezuela; and the \\ Department of Human Genetics, University of Michigan School of Medicine, Ann Arbor, Michigan, USA
}

SUMmARY A genetic analysis of the presence of $\mathrm{HBsAg}$ in a population of which $7 \cdot 2 \%$ of the members were positive is presented. Though the ratios of carriers: non-carriers were generally in good agreement with expectation if the carrier state were determined by homozygosity for a single recessive gene, the two examples of mating most critical to a test of the hypothesis, carrier $\times$ carrier, yielded 2 normal children among 4 in one family, and one normal child, the only offspring, in the second family. Other investigators have reported similar findings. We conclude that the hypothesis of simple recessive inheritance cannot be sustained.

Familial clustering of chronic carriers of hepatitis B surface antigen ( $\mathrm{HBsAg}$ ) has frequently been reported in different populations with high or low incidence of the antigen (Blumberg et al., 1966; Carbonara et al., 1970; Ceppellini et al., 1970; Szmuness et al., 1973, 1975; Reeves et al., 1975), but the significance of the concentration is not clear. Blumberg et al. $(1966,1969)$ proposed that this clustering of the HBsAg carriers was due to autosomal recessive inheritance of susceptibility to the carrier state, a mode of inheritance also proposed independently by Ceppellini et al. (1970) (see also Carbonara et al., 1970). The formal tests of these investigators for agreement of the data with the ratios characteristic of recessive inheritance implicitly assumed that all subjects in the populations studied had been exposed to the hepatitis B virus at an early age, either by vertical transmission or through postnatal contacts, so that they could be expected to express this genotype. If one accepts this assumption, then the most critical of all mating types to a test of the hypothesis is a marriage of two HBsAg carriers, which should yield only affected offspring. This mating is especially critical if the results of other types of matings are consistent with the hypothesis, and also suggests that the assumption concerning exposure is fulfilled. There were no such marriages in the material reported by Blumberg et al. (1966,

\footnotetext{
${ }^{1}$ The financial support of the US National Science Foundation and the US Atomic Energy Commission (now Department of Energy) is gratefully acknowledged.

Received for publication 22 July 1978
}

1969), and only one such marriage in the material of Ceppellini et al. (1970). Petrakis (1972) drew attention to the fact that in the one family characterised by two HBsAg carrier parents in this latter material, only 2 of 7 children were positive. Vyas (1974) reported a marriage of Chinese carrier parents in which none of the 3 children was a carrier, and one, in fact, had specific anti-HBsAg antibodies, with a titre of 256 in haemagglutination assay. More recently, Stevens and Beasley (1976) showed that in a Taiwanese sample, only 30 of 47 children were HBsAg positive $(63.8 \%)$ when both parents were positive, but when the mother was positive and the father anti-HBsAg positive, 57 of 100 children, a similar proportion were positive. Since, in the latter case the father is either heterozygous or homozygous for the normal (dominant) allele, neither of these outcomes corresponds to expectation of recessive inheritance. These and other findings, to be mentioned later, have led a number of people to serious reservations concerning the hypothesis of recessive inheritance (Lederberg, 1972; Petrakis, 1972; Vyas, 1974; Stevens and Beasley, 1976).

In a previous paper (Soyano et al., 1976), we reported that the frequency of $\mathrm{HBsAg}$ among the Yanomama Indians of southern Venezuela, tested by the immunodiffusion technique, was $7 \cdot 4 \%$, but it varied within villages from 0 to $31 \%$. In view of the intimacy of contact of all individuals in a Yanomama village, this population was thought to provide an opportunity for a further test of the recessive inheritance of susceptibility to the carrier state. 


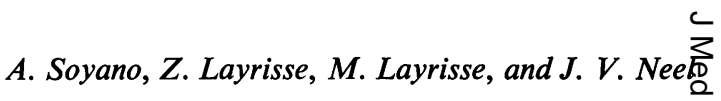

\section{Materials and methods}

The Yanomama Indians are one of the largest South American tribes to have remained isolated from other Indian tribes and Creole populations (Layrisse and Wilbert, 1966; Chagnon, 1968; Neel et al., 1977). A multidisciplinary study of these Indians was carried out between 1966 and 1974 by the Department of Human Genetics of the University of Michigan and the Venezuelan Institute of Scientific Research. In addition to the cultural, demographic, anthropometric, and health studies which were performed, blood was collected from more than 3500 subjects to test blood group systems and other elements. During the collection of blood a special effort was made to cover the total population of each village, with the exception of children below 2 years of age, from whom only a few samples were taken. Samples were tested for the presence of HBsAg by immunodiffusion (ID) in agarose, according to Prince (1968). The origin and specificity of the anti-HBsAg serum used has been described previously (Soyano et al., 1976). Radioimmunoassay (RIA, Ausria II-125, Abbott Laboratories, North Chicago, Illinois) was also performed on samples from 80 families.

\section{Results}

Since our first report on the frequency of $\mathrm{HBsAg}$ among the Yanomama (Soyano et al., 1976), 456 new individuals have been tested by RIA. These results are summarised in Table 1 . The overall frequency of $\mathrm{HBsAg}$ positive individuals in this new series was $6.8 \%$, and again it varied within villages from 0 to $28.6 \%$. Taken together both series show an overall frequency of $7 \cdot 2 \%(117 \mathrm{HBsAg}$ positive cases in 1625 individuals tested). Frequency in males $(10.1 \%)$ was higher than in females $(5.7 \%)$. This difference is statistically significant $(0.05>P>0.02)$. Within this material 132 nuclear families can be identified. The circumstance of having at hand typings of each individual for 10 to 14 blood group systems which showed polymorphism in this tribe allowed us to identify the majority of extramarital children and remove them from the series.

Available for genetic analysis were 132 families with a total of 518 members and an average of 2.07 sibs per family. All of them were studied by ID, while only 80 families were studied by RIA. Despite the relatively high frequency of HBsAg carriers in this population, only 23 of the ID-tested and 20 of the RIA-tested families had at least one HBsAg positive child (Table 2). There were two possible carrier $\times$ carrier matings (no 59 and 123). In both cases, the parents were positive by RIA but negative
Table 1 Frequency of $\mathrm{HBs} \mathrm{Ag}$ in different Yanomama villages

\begin{tabular}{|c|c|c|c|}
\hline Village & $\begin{array}{l}\text { No of individuals } \\
\text { tested }\end{array}$ & $\begin{array}{l}\text { HBsAg } \\
\text { positive }\end{array}$ & $\%$ \\
\hline \multicolumn{4}{|l|}{ Central villages } \\
\hline 03 KP Hakama & 62 & 0 & 0 \\
\hline 03 LMN Wutahai & 59 & 4 & $6 \cdot 7$ \\
\hline 03 Q Fafanabak & 24 & 1 & $4 \cdot 2$ \\
\hline 03 W Parimi & 63 & 3 & $4 \cdot 8$ \\
\hline Total & 208 & 8 & $3 \cdot 8$ \\
\hline \multicolumn{4}{|l|}{ Southern villages } \\
\hline 03 RS Horeba & 61 & 5 & $8 \cdot 2$ \\
\hline 03 T Ora & 48 & 1 & $2 \cdot 1$ \\
\hline Total & 109 & 6 & $5 \cdot 5$ \\
\hline \multicolumn{4}{|l|}{ Northern villages } \\
\hline 03 U Ashikama & 32 & $\mathbf{0}$ & 0 \\
\hline \multicolumn{4}{|l|}{ Eastern villages } \\
\hline $03 \mathrm{X}$ & 68 & 12 & $17 \cdot 6$ \\
\hline \multicolumn{4}{|l|}{ Miscellaneous } \\
\hline $03 \mathrm{~V}$ & 18 & 0 & 0 \\
\hline $03 \mathrm{Y}$ & 14 & 4 & $28 \cdot 6$ \\
\hline $03 \mathrm{Z}$ & 7 & 1 & $14 \cdot 3$ \\
\hline Grand total & 456 & 31 & $6 \cdot 8$ \\
\hline
\end{tabular}

Table 2 Yanomama families segregating for $\mathrm{HBs} A \mathrm{~g}$

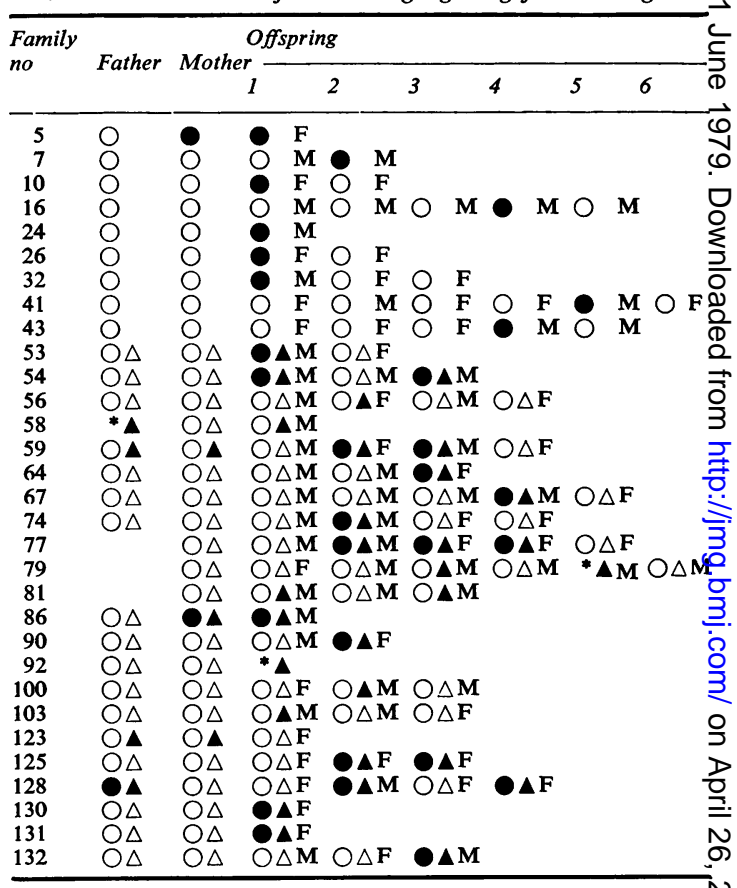

*, not tested by ID.

Presence or absence of HBsAg is indicated by a closed or open symboln respectively. Individuals tested by ID are indicated by $O$ or $O$, and those tested by RIA by $\Delta$ or $\Delta$. The letter following the symboP indicates sex. In the 3 families in which one parent was not tested $(77,79$, and 81$)$ it was assumed that the missing parent was HBsAg를 negative.

by ID. Since we have previously shown the greater sensitivity of the RIA technique in the Yanomam $\mathbb{\pi}^{+}$ (Soyano et al., 1976), we consider these to be carrie $\times$ carrier matings. In family no 59,2 of 4 childre 
were normal, while in family no 123 , the only offspring was normal.

The remaining matings were subdivided as to whether one or neither parent was HBsAg positive and the agreement of the ratio of carriers : noncarriers in the offspring on a recessive inheritance hypothesis obtained by two procedures, that of Smith (1956) and Li and Mantel (1968), as was done by Blumberg et al. $(1966,1969)$ in the original studies. Tables 3 and 4 present the results of the analysis by the method of Smith (1956), Table 3 dealing with the results of the ID test and Table 4 with the results of the RIA test. For the HBsAg positive $\times \mathrm{HBsAg}$ negative matings, identical results were obtained by the immunodiffusion and the RIA tests (upper part of Tables 3 and 4, respectively). There was good agreement between the observed and expected numbers, though the numbers were too small to use the $\chi^{2}$ test with confidence. For the HBsAg negative $\times$ HBsAg negative matings, there was again not only a close agreement between the total HBsAg positive observed and expected values, but also a good agreement for each family size on its own. In the ID results (Table 3), if the genetic hypothesis is correct, then $25.51 \mathrm{HBsAg}$ positive sibs were expected and 24 were seen, a very close fit $\left(\chi^{2}=0.38 ; 0.7>P>0.5\right)$. The agreement of the totals can also be checked by comparing the difference $\mid$ observed-expected $\mid=1 \cdot 51$, with its standard error, $\mathrm{SE}=\sqrt{\text { Variance }}=2 \cdot 43$. Since the difference | observed-expected| is less than its standard error, this indicates good agreement. An even better agreement is observed in the RIA results (Table 4). In this case, $22 \cdot 39 \mathrm{HBsAg}$ positive sibs were expected and 23 were seen $\left(\chi^{2}=0.075\right.$ $0 \cdot 80>\mathrm{P}>0 \cdot 70)$; the difference |observed-expected $=0 \cdot 61$, is much less than its standard error, $2 \cdot 21$.

The results of applying the Li-Mantel test are shown in Table 5. With this method, only matings of the HBsAg negative $\times$ HBsAg negative type are

Table 3 Segregation of $\mathrm{HBs} \mathrm{Ag}$ in sibships with at least one antigen positive member: results of the ID test

\begin{tabular}{|c|c|c|c|c|c|c|}
\hline $\begin{array}{l}\text { No of sibs } \\
\text { in family }\end{array}$ & $\begin{array}{l}\text { No o } \\
\text { fami }\end{array}$ & $\begin{array}{l}\text { of } \\
\text { ilies }\end{array}$ & $\begin{array}{l}\text { Total noof } \\
\text { sibs }\end{array}$ & $\begin{array}{l}\text { HBsAg } \\
\text { observed }\end{array}$ & $\begin{array}{l}\text { HBsAg } \\
\text { expected }\end{array}$ & Variance \\
\hline \multicolumn{7}{|c|}{ (1) Mating type: HBsAg positive $\times H B s A g$ negative } \\
\hline 1 & 3 & & 3 & 3 & 3.000 & 0.000 \\
\hline 4 & 1 & & 4 & 2 & $2 \cdot 133$ & 0.782 \\
\hline Total & 4 & & 7 & 5 & $5 \cdot 133$ & 0.782 \\
\hline$\chi^{2}=0.022$ & & $0.9=$ & $P>0.8$ & & & \\
\hline \multicolumn{7}{|c|}{ (2) Mating type: HBsAg negative > } \\
\hline 1 & 2 & & 2 & 2 & $2 \cdot 000$ & 0.000 \\
\hline 2 & 5 & & 10 & 5 & $5 \cdot 715$ & 0.610 \\
\hline 3 & 5 & & 15 & 7 & $6 \cdot 485$ & $1 \cdot 315$ \\
\hline 4 & 2 & & 8 & 3 & 2.926 & 0.840 \\
\hline 5 & 4 & & 20 & 6 & $6 \cdot 556$ & $2 \cdot 368$ \\
\hline 6 & 1 & & 6 & 1 & $1 \cdot 825$ & 0.776 \\
\hline Total & 19 & & 61 & 24 & $25 \cdot 507$ & $5 \cdot 910$ \\
\hline \multicolumn{2}{|c|}{$\chi^{2}=0.3843$} & \multicolumn{4}{|c|}{$0.7>\mathrm{P}>0.5$} & \\
\hline
\end{tabular}

Table 4 Segregation of HBs Ag in sibships with at least one antigen positive member: results of the RIA test

\begin{tabular}{|c|c|c|c|c|c|c|}
\hline $\begin{array}{l}\text { No of sibs } \\
\text { in family }\end{array}$ & $\begin{array}{l}\text { No } \\
\text { fami }\end{array}$ & $\begin{array}{l}\text { of } \\
\text { ilies }\end{array}$ & $\begin{array}{l}\text { Total no } \\
\text { of sibs }\end{array}$ & $\begin{array}{l}\text { HBsAg } \\
\text { observed }\end{array}$ & $\begin{array}{l}\text { HBsAg } \\
\text { expected }\end{array}$ & Variance \\
\hline \multicolumn{4}{|c|}{ (I) Mating type: } & \multicolumn{2}{|c|}{$\times$ HBsAg negative } & \\
\hline 1 & 2 & & 2 & 2 & $2 \cdot 000$ & 0.000 \\
\hline 4 & 1 & & 4 & 2 & $2 \cdot 133$ & $0 \cdot 782$ \\
\hline Total & 3 & & 6 & 4 & $4 \cdot 133$ & 0.782 \\
\hline$\gamma^{2}=0.022$ & & $0 \cdot 9$ & $P>0.8$ & & & \\
\hline \multicolumn{4}{|c|}{ (2) Mating type: } & \multicolumn{2}{|c|}{$\times$ HBsAg negative } & \\
\hline 1 & 3 & & 3 & 3 & $3 \cdot 000$ & 0.000 \\
\hline 2 & 2 & & 4 & 2 & $2 \cdot 286$ & $0 \cdot 244$ \\
\hline 3 & 7 & & 21 & 10 & 9.079 & $1 \cdot 841$ \\
\hline 4 & 2 & & 8 & 2 & $2 \cdot 926$ & 0.840 \\
\hline 5 & 2 & - & 15 & 4 & $3 \cdot 278$ & $1 \cdot 184$ \\
\hline 6 & 1 & & 6 & 2 & $1 \cdot 825$ & 0.776 \\
\hline Total & 17 & & 57 & 23 & $22 \cdot 394$ & $4 \cdot 885$ \\
\hline \multicolumn{2}{|c|}{$\chi^{2}=0.0752$} & \multicolumn{2}{|c|}{$0.8>\mathrm{P}>0.7$} & & & \\
\hline
\end{tabular}

Table 5 Calculation by Li and Mantel's (1968) methods of segregation ratio in $\mathrm{HBs}$ Ag negative $\times$ HBsAg negative matings

\begin{tabular}{lllll}
\hline & $t$ & $j$ & $r$ & $p^{\prime}$ \\
\hline ID & 61 & 15 & 24 & $0 \cdot 196$ \\
RIA & 57 & 12 & 23 & 0.244 \\
\hline
\end{tabular}

$t$, total no of children who are the issue of HBsAg negative $\times$ HBsAg negative matings.

$\mathrm{j}$, no of children who are the only recessive offspring in each family. $\mathrm{r}$, no of recessive children.

$p^{\prime}, \frac{r-j}{t-j}$

taken into account. For an 'ideal' recessive trait, the proportion of recessive children would be $0 \cdot 25$. For the ID results, the estimation of the proportion of $\mathrm{HBsAg}$ positive children was $0 \cdot 20$, a good fit. For the RIA results its value was $\mathbf{0 \cdot 2 4}$, an excellent fit.

As noted earlier, the proportion of $\mathrm{HBsAg}$ individuals per village varied from 0 to $31 \%$. Such wide differences between the villages of a single tribe might at first appear incompatible with the hypothesis of simple recessive inheritance. However, we have documented extensive genetic microdifferentiation within these Yanomama villages (Gershowitz et al., 1972; Layrisse et al., 1973), so that such wide variations in the frequency of what, by hypothesis, would have to be a relatively common recessive gene are conceivable. On the other hand, the very magnitude of this variation precludes any attempt at an analysis based on obtaining a postulated gene frequency from the square root of the phenotype frequency in the entire tribe, and, unfortunately, the village samples are too small to justify this procedure. Incidentally, one line of evidence for the genetic nature of the susceptibility to becoming a carrier developed by Blumberg $e t$ al. $(1966,1969)$ was the familial nature of the carrier 
state. However, in reaching this conclusion they pooled data from populations almost as heterogeneous as Yanomama villages, and pooling such populations will always provide a familial aggregation, even if a disease is entirely non-genetic.

\section{Discussion}

The Yanomama undoubtedly represent one of the most primitive populations yet surveyed for the frequency of HBsAg. The intimacy of life in an Indian village must be seen to be believed. With respect specifically to the epidemiology of hepatitis $B$, the maternal practice of premastication of the young child's food should be mentioned, as well as the many different breasts at which an infant may nurse in the course of a single day. At an older age level, boluses of tobacco are frequently shared, and vigorous scratching of each other with hands innocent of personal hygiene is common. They also groom each other for lice, frequently crushing the fruits of the hunt between their teeth. Whatever the precise epidemiology of hepatitis $B$, these would seem to be favourable circumstances for hepatitis $B$ transmission. However, only 3 among 938 Yanomama tested had anti-HBsAg antibody, so that $92.7 \%$ of all Yanomama were non-HBsAg, nonanti-HBsAg. Both the need for, and the difficulties inherent in, proper longitudinal studies of populations of this nature, to define the duration of both the HBsAg and anti-HBsAg states, are clear.

We find ourselves in a paradoxical position as regards the recessively inherited nature of the susceptibility to becoming a chronic carrier for HBsAg. On the one hand, the matings most critical to a test of this hypothesis, carrier $\times$ carrier, which should yield all carrier children, have consistently failed to do so. This finding can be explained as being due to the failure of some susceptible children to have developed the carrier state at the time of study. On the other hand, other tests of adherence to the ratios expected in recessive inheritance, in sibships ascertained through the occurrence of an affected child, and subdivided for analysis depending on whether neither or one parent was a carrier, have shown excellent agreement with the hypothesis of recessivity. In addition to the findings already cited and our own in this paper, we should mention the similar findings of Helske and Nevanlinna (1973) in Finland. The paradox is heightened by the significant difference between the frequency of affected males and females in our series and others, a finding not characteristic of autosomal recessive inheritance, as well as a significantly lower frequency in several series of HBsAg individuals in the older age groups (Soyano et al., 1976). We cannot 'explain' the results of the carrier $\times$ carrier matings by nof penetrance, but then accept the complete penetrance implied by the agreement with the hypothesis other types of matings.

The formation of anti-HBsAg antibodies shour be incompatible with the genetic predisposition ti becoming a carrier of HBsAg. The most critical evidence on the genetic hypothesis would be of the type produced by Vyas (1974) quoted earlier. Hover ever, as noted above, only 3 of 938 Yanomama tested exhibited significant titres of anti-HBsAg antibody (Soyano et al., 1976), and none of these 3 was $\dot{\phi}$ child of the 2 carrier $\times$ carrier matings. Such a lo요 frequency of anti-HBsAg antibody scarcely seem compatible with the assumption of universal exposure to the hepatitis B virus among the Yanomama, and yet, as noted above, certain genetic ratios would demand that such exposure had occurred and $\mathrm{a} \mathbb{\Psi}$ susceptible children manifested the genotype.

In our opinion, the weight of the evidence is clearly against a simple recessive hypothesis, though some type of genetic predisposition to develop the carrier state cannot be excluded. The family clustering undoubtedly, to some extent, depends on the vertical transmission of hepatitis B virus (Stevens and Beasley, 1976) and spread of virus through close personal contact. The critical studies of the future should include tests for anti-HBsAg antibod together with tests for HBsAg. In the meantime, wa seem to have the latest example of the 'simulation Mendelism', a well-known pitfall for genetio investigation (cf, Edwards, 1960).

\section{References}

Blumberg, B., Friedlaender, J., Woodside, A., Sutnick, A. and London, W. T. (1969). Hepatitis and Au: autosoma recessive inheritance of susceptibility to infection in humans. Proceedings of the National Academy of Sciencess of the United States of America, 62, 1108-1115.

Blumberg, B., Melartin, L., Guinto, R., and Werner, 8. (1966). Family studies of a human isoantigen system (Australia antigen). American Journal of Human Genetic, 18, 594-608.

Carbonara, A., Trinchieri, G., Bedarida, G., and Filippi, 8 . (1970). A caucasian population with a high frequency Au 'carriers': genetic analysis of the condition. $V \overline{Q D X}$ Sanguinis, 19, 288-294.

Ceppellini, R., Bedarida, G., Carbonara, A., Trinchieri, G. and Filippi, G. (1970). High frequency and family clusters ing of Au antigen in some Italian populations. Atti Convegus

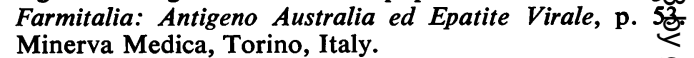

Chagnon, N. A. (1968). Yanomama: The Fierce Peope. Holt, Rinehart, and Winston, New York.

Edwards, J. H. (1960). The simulation of Mendelism. Acefa Genetica et Statistica Medica, 10, 63-70.

Gershowitz, H., Layrisse, M., Layrisse, Z., Neel, J. \$ Chagnon, N. A., and Ayres, M. (1972). The gene茀 structure of a tribal population, the Yanomama Indians. $\mathbf{H}$. Eleven blood group systems and the ABH-Le secre traits. Annals of Human Genetics, 35, 261-269.

(1)


Helske, T., and Nevanlinna, H. R. (1973). Familial accumulation of carriers of $\mathrm{Au}$ antigen. Journal of Medical Genetics, 10, 270-271.

Layrisse, M., and Wilbert, J. (1966). Indian Societies of Venezuela. Their Blood Group Types, p. 318. Editorial Sucre, Caracas.

Layrisse, Z., Layrisse, M., Malavé, I., Terasaki, P., Ward, R. H., and Neel, J. V. (1973). Histocompatibility antigens in a genetically isolated American Indian tribe. American Journal of Human Genetics, 25, 493-509.

Lederberg, J. (1972). Genetic predisposition to hepatitis. In Hepatitis and Blood Transfusion, pp. 89-93. Ed. by G. N. Vyas, H. A. Perkins, and R. Schmid. Grune and Stratton, New York.

Li, C. C., and Mantel, N. (1968). A simple method of estimating the segregation ratio under complete ascertainment. American Journal of Human Genetics, 20, 61-81.

Neel, J. V., Layrisse, M., and Salzano, F. (1977). Man in the tropics: Yanomama Indians. In Population Structure and Human Variation, pp. 109-142. Ed. by G. A. Harrison. International Biological Programme, Vol. II. Cambridge University Press, Cambridge.

Petrakis, N. (1972). Genetic predisposition to hepatitis. In Hepatitis and Blood Transfusion, pp. 85-87. Ed. by G. N. Vyas, H. A. Perkins, and R. Schmid. Grune and Stratton, New York.

Prince, A. (1968). Antigen detected in the blood during the incubation period of serum hepatitis. Proceedings of the National Academy of Sciences of the United States of America, 60, 814-821.
Reeves, W. C., Peters, C. J., Moon, T. E., and Purcell, R. H. (1975). Familial clustering of hepatitis-B surface antigen among Panamanian Indians. Journal of Infectious Diseases, 131, 67-70.

Smith, C. A. B. (1956). A test for segregation ratios in family data. Annals of Human Genetics, 20, 257-265.

Soyano, A., Malavé, I., Walder, R., Layrisse, Z., and Layrisse, M. (1976). Hepatitis-B antigen in an isolated Indian population (the Yanomama) of Southern Venezuela. Revista Brasileira de Pesquisas Médicas e Biologicas, 9, 247-253.

Stevens, C. E., and Beasley, R. P. (1976). Lack of an autosomal recessive genetic influence in vertical transmission of hepatitis B antigen. Nature, 260, 715-716.

Szmuness, W., Harley, E. J., and Prince, A. M. (1975). Intrafamilial spread of asymptomatic hepatitis-B. American Journal of Medical Science, 270, 293-304.

Szmuness, W., Prince, A. M., Hirsch, R. L., and Brothmann, B. (1973). Family clustering of hepatitis-B infection. New England Journal of Medicine, 289, 1162-1166.

Vyas, G. N. (1974). Evidence against recessive inheritance of susceptibility to the chronic carrier state for hepatitis B antigen. Nature, 248, 159-160.

Requests for reprints to Dr A. Soyano, Instituto Venezolano de Investigaciones Científicas, Apartado 1827, Caracas 101, Venezuela. 